\title{
Association of single nucleotide polymorphisms with renal cell carcinoma in Algerian population
}

\author{
F. Z. Bensouilah ${ }^{1,2^{*}}$, Dj. Chellat-Rezgoune ${ }^{1,2}$, M. A. Garcia-Gonzalez ${ }^{3}$, N. Carrera ${ }^{3}$, N. Abadi ${ }^{2}$, A. Dahdouh ${ }^{4}$ \\ and D. Satta ${ }^{1,2}$
}

\begin{abstract}
Background: Renal cell carcinoma (RCC) is a common malignant tumor of the urinary system. The etiology of RCC is a complex interaction between environmental and multigenetic factors. Genome-wide association studies have identified new susceptibility risk loci for RCC. We examined associations of genetic variants of genes that are involved in metabolism, DNA repair and oncogenes with renal cancer risk. A total of 14 single nucleotide polymorphisms (SNPs) in 11 genes (VEGF, VHL, ATM, FAF1, LRRIQ4, RHOBTB2, OBFC1, DPF3, ALDH9A1 and EPAS1) were examined.
\end{abstract}

Methods: The current case-control study included 87 RCC patients and 114 controls matched for age, gender and ethnic origin. The 14 tag-SNPs were genotyped by Sequenom MasSARRAY ${ }^{\circledR}$ iPLEX using blood genomic DNA.

Results: Genotype CG and allele G of ATM rs 1800057 were significantly associated with RCC susceptibility ( $p=0.043$; $\mathrm{OR}=8.47 ; \mathrm{Cl}=1.00-71.76)$. Meanwhile, we found that genotype AA of $r 567311347$ polymorphism could increase the risk of $\mathrm{RCC}(p=0.03 ; \mathrm{OR}=2.95 ; \mathrm{IC}=1.10-7.89)$. While, genotype TT and T allele of ALDH9A $1 \mathrm{rs} 3845536$ were observed to approach significance for a protective role against $\mathrm{RCC}(p=0.007 ; \mathrm{OR}=0.26 ; \mathrm{Cl}=0.09-0.70)$.

Conclusion: Our results indicate that ATM rs 1800057 may have an effect on the risk of RCC, and suggest that ALDH9A1 was a protective factor against RCC in Algerian population.

Keywords: Renal cell carcinoma, Polymorphism, Sequenom MassARRAY ${ }^{\circledR}$ iPLEX, ATM, ALDH9A1

\section{Background}

Kidney cancer is predicted to be the 15 th most common cancer worldwide, with approximately 403,000 new cases and 175,000 deaths from the disease in 2018 [1]. Renal cell carcinoma (RCC) is the predominant form of kidney malignancy, although there has been an increased incidence of RCC globally, with higher incidences and mortality rates reported in men and Caucasian populations. Several occupational and lifestyle factors may affect the risk of RCC such as smoking, obesity, hypertension and socioeconomic status. Furthermore, knowing

\footnotetext{
*Correspondence: fatima-zohra.bensouilah@umc.edu.dz

1 Department of Animal Biology, Laboratory of Molecular and Cellular

Biology, University Constantine 1, Constantine 25000, Algeria

Full list of author information is available at the end of the article
}

well the related factors can contribute to make successful prevention possible for a disease [2,3]. With the aim of prevention, we should take into account the fact that RCC consists of different types with specific genetic molecular characteristics, although most RCCs are sporadic and $2-4 \%$ have a hereditary cause. Several genetic diseases are associated with RCC, including VHL syndrome, hereditary papillary renal carcinoma (HPRCC ), hereditary leiomyomatosis RCC, Birt-Hogg-Dube $(B H D)$ syndrome, chromosome 3 translocation, and tuberous sclerosis (TCS1, TCS2) [4]. The most common type of RCC, clear cell renal cell carcinoma (ccRCC), is closely associated with $V H L$ gene mutations that lead to stabilization of hypoxia inducible factors (HIF-1a and HIF-2a, also known as HIF1A and EPAS1) in both sporadic and familial forms [5]. An overaccumulation of 
HIFs increased transcription of their downstream genes, considered to be important in cancer, including vascular endothelial growth factor (VEGF) [6]. The VHL/HIF/ $V E G F$ is a functional pathway that plays a major role in the development and progression of RCC. Therefore, in the present study, we investigate the association of three functional SNPs (-2578C/A [rs699947], -460T/C [rs833061] and +405C/G [rs2010963]) in VEGF gene, and two SNPs (rs1642742 and rs779805) in the VHL gene with RCC risk. Furthermore, other new loci may also be involved in genetic predisposition to RCC.

Recently, several genome-wide association studies (GWAS) were conducted in the aim to identify additional new risk loci for RCC. Here, we investigate nine risk loci identified by previous GWAS [7-9] to be related with RCC risk, within European population, at chromosome bands 1p32.3, 3p22.1, 3q26.2, 8p21.3, 10q24.33- q25.1, 14q24.2, 11q22, 1q24.1 and 2p21.

Our study aimed to investigate the role of fourteen genetic polymorphisms (SNPs) in RCC Algerian patients. The selected variants were chosen on the basis of their positive correlation with renal carcinoma (VEGF, VHL) or on the basis of their identification as new loci in the latest GWAS studies [7-9]. It should be mentioned that these selected SNPs were considered for the first time in our study in Algerian RCC cases.

\section{Methods}

\subsection{Study population}

This case-control study included 87 patients diagnosed with RCC at the Uro-Nephrology Hospital "The Department of Urology and Renal Transplantation", Constantine, Algeria, between 2015 and 2017. All patients had undergone radical or partial nephrectomy, with histopathologically confirmed RCC. Patients were excluded from our study if they had a prior history of other tumors. Before recruitment, a standard questionnaire was administered through face-to-face interviews to collect demographic and clinico-pathological characteristics data of patients.

The control group included 114 healthy volunteers (48 women and 66 men) who were free of any chronic diseases and having no history of any cancer. All patients and controls were from North of Algeria and all of them signed informed consent to participate in this study, which was approved by the ethics committee of our hospital.

\subsection{Blood samples and genotyping}

Genomic DNA was extracted from the peripheral blood leukocytes using standard $\mathrm{NaCl}$ method according to the protocol suggested by Miller and co-workers [10]. DNA quality and concentration were evaluated by Nanodrop spectrophotometer. The selected 14 tag-SNPs were genotyped using the Sequenom MassARRAY ${ }^{\circledR}$ iPLEX Platform from Agena Bioscience. The iPLEX workflow begins by using Assay Design Suite (ADS) software to design polymerase chain reaction (PCR) and iPLEX extension primers for each SNP, which are available upon request. SNP amplification assays were performed according to the manufacturer's instructions. Briefly, $2 \mu \mathrm{l}$ of sample DNA was placed in $3 \mu \mathrm{l}$ of reaction solution containing: $0.4 \mu \mathrm{l}$ of $25 \mathrm{mM} \mathrm{MgCl} 2,0.1 \mu \mathrm{l}$ of $25 \mathrm{mM} \mathrm{dNTP}, 0.5 \mu \mathrm{l}$ of $10 \times$ buffer, $1 \mu \mathrm{l}$ of primer mix and $0.4 \mu \mathrm{l}$ of $5 \mathrm{U}$ Platinum Taq DNA polymerase in $0.8 \mu \mathrm{l}$ of nuclease-free water. The PCR cycling conditions were: $95^{\circ} \mathrm{C}$ for $2 \mathrm{~min}$ and 45 cycles of $95^{\circ} \mathrm{C}$ for $30 \mathrm{~s}, 56^{\circ} \mathrm{C}$ for $30 \mathrm{~s}$ and $72{ }^{\circ} \mathrm{C}$ for $1 \mathrm{~min}$. The PCR product was purified using the shrimp alkaline phosphatase (SAP) method, which included $0.17 \mu \mathrm{l}$ of $10 \times$ SAP buffer, $1.7 \mu \mathrm{l}$ SAP enzyme, $1.53 \mu \mathrm{lddH} 2 \mathrm{O}$ and $5 \mu \mathrm{PCR}$ product, beginning at $37^{\circ} \mathrm{C}$ for $40 \mathrm{~min}$ and then $85^{\circ} \mathrm{C}$ for $5 \mathrm{~min}$. The iPLEX extension reaction was carried out in a 9- $\mu \mathrm{l}$ volume containing $2 \mu \mathrm{l}$ of reaction Mix (MassARRAY ${ }^{\circledR}$ ), $7 \mu$ l PCR products and performed in 40 cycles of 95,52 and $80{ }^{\circ} \mathrm{C}$ for $5 \mathrm{~s}$, respectively. The iPLEX reaction products were also cleaned up using the Resin method (clean resin) and transferred from 384-well microtiter plate on 384-sample SpectroCHIP ${ }^{\circledR}$ using Nanodispenser. The genotype of each sample was attributed by MALDI-TOF mass spectrometry using sequenom supplies software (SpectroTyper 4.0) that automatically translates the mass of the observed primers into a genotype for each reaction. About 10\% of the samples were randomly selected for repeated assays, and the results were all concordant.

\subsection{Statistical analysis}

The genotype distributions of all these SNPs were in Hardy-Weinberg equilibrium using Pearson Chi-square test. $X^{2}$ test was used to compare genotype frequencies between cases and controls, and to evaluate the relationships of SNPs genotypes with histologic type of our patients. Odds ratios (ORs) and $p$ values were also calculated. $p<0.05$ was considered statistically significant. All analysis were done using $\mathrm{R}$ software version (3.5.2).

\section{Results}

\subsection{Subjects characteristics}

The demographic and clinical characteristics of the study subjects are shown in Table 1. A total of 201 participants were included, 87 patients with RCC and 114 age-and gender matched healthy controls. The mean ages of the cases and controls were $56.27 \pm 13.91$ (range, $25-88$ years old) years and $51.71 \pm 13.64$ (range, 23-84 years old) years, respectively. Of the 87 RCC patients, 30 (34.5\%) had pT3 stage of RCC, 39 (44.8\%) had grade II of RCC, 
Table 1 Demographic and clinical characteristics of RCC cancer cases and controls

\begin{tabular}{|c|c|c|}
\hline Characteristics & Cases & Controls \\
\hline Age (mean $\pm S D), y r$ & $56.27 \pm 13.91$ & $51.71 \pm 13.64$ \\
\hline \multicolumn{3}{|l|}{ Gender (\%) } \\
\hline Male & $51(58.6)$ & $66(58)$ \\
\hline Female & $36(41.4)$ & $48(42)$ \\
\hline \multicolumn{3}{|l|}{ Tumor size (\%) } \\
\hline$>7$ & $47(54.0)$ & \\
\hline$\leq 7$ & $35(40.2)$ & \\
\hline Unknown & $5(5.7)$ & \\
\hline \multicolumn{3}{|l|}{ Tumor stage (\%) } \\
\hline pT1 & $28(32.2)$ & \\
\hline pT2 & $21(24.1)$ & \\
\hline pT3 & $30(34.5)$ & \\
\hline PT4 & $5(5.7)$ & \\
\hline Unknown & $3(3.4)$ & \\
\hline \multicolumn{3}{|l|}{ Tumorgrade (\%) } \\
\hline I & $1(1.1)$ & \\
\hline$\|$ & $39(44.8)$ & \\
\hline III & $28(32.2)$ & \\
\hline IV & $13(14.9)$ & \\
\hline Unknown & $6(6.9)$ & \\
\hline \multicolumn{3}{|l|}{ Location (\%) } \\
\hline Left & $47(54)$ & \\
\hline Right & $40(46)$ & \\
\hline \multicolumn{3}{|l|}{ Histopathology (\%) } \\
\hline Clear-cell carcinoma & $54(62.1)$ & \\
\hline Chromophobe cell carcinoma & $14(16.1)$ & \\
\hline Papillary renal cell carcinoma & $12(13.7)$ & \\
\hline Bellini-duct carcinoma & $2(2.3)$ & \\
\hline Renal mucinous tubular carcinoma & $2(2.3)$ & \\
\hline Primary renal lymphoma (PRL) & $2(2.3)$ & \\
\hline Renal neuroendocrine tumor (NET) & $1(1.15)$ & \\
\hline
\end{tabular}

and approximately 47 (54\%) have larger tumors $(>7 \mathrm{~cm})$. The majority of patients $54(62.1 \%)$ had the conventional clear-cell carcinoma. Fourteen patients (16.1\%) had chromophobe carcinoma. Twelve patients (13.7\%) had papillary carcinoma and other rare subtypes of RCC were also found including Bellini-duct carcinoma, mucinous tubular carcinoma, primary renal lymphoma (PRL) accounted for $(2.3 \%)$, respectively, and renal neuroendocrine tumor (NET) for $(1.15 \%)$ of all the carcinoma.

\subsection{Genotypic and allelic frequencies of selected 14 tag-SNPs in the RCC cases and controls}

Table 2 shows the genotypic and allelic distributions of the 14 tested polymorphisms in cases and controls with estimated ORs. The selected 14 tag-SNPs were
Table 2 Genotypic and allelic frequencies of 14 tag-SNPs in the RCC cases and controls

\begin{tabular}{|c|c|c|c|c|}
\hline & $P 1^{a}$ & OR $(95 \% \mathrm{Cl})^{a}$ & $P 2^{a}$ & HWE \\
\hline \multicolumn{5}{|l|}{ VEGF } \\
\hline rs2010963 & 0.775 & $1.16(0.77-1.73)$ & 0.47 & 0.51 \\
\hline rs699947 & 0.416 & $1.31(0.87-1.95)$ & 0.21 & 0.91 \\
\hline rs833061 & 0.475 & $1.27(0.85-1.89)$ & 0.26 & 0.96 \\
\hline \multicolumn{5}{|l|}{ VHL } \\
\hline rs 1642742 & 0.663 & $0.88(0.59-1.31)$ & 0.61 & 0.82 \\
\hline rs779805 & 0.691 & $0.88(0.59-1.32)$ & 0.61 & 0.88 \\
\hline \multicolumn{5}{|l|}{ FAF1 } \\
\hline rs4381241 & 0.417 & $1.27(0.85-1.89)$ & 0.26 & 0.40 \\
\hline rs67311347 & 0.086 & $1.49(0.99-2.25)$ & 0.05 & 0.20 \\
\hline \multicolumn{5}{|l|}{ LRRIQ4 } \\
\hline rs10936602 & 0.248 & $0.69(0.39-1.20)$ & 0.21 & 0.70 \\
\hline \multicolumn{5}{|l|}{ RHOBTB2 } \\
\hline rs 2241261 & 0.604 & $0.89(0.60-1.33)$ & 0.61 & 0.91 \\
\hline \multicolumn{5}{|l|}{$O B F C 1$} \\
\hline rs11813268 & 0.869 & $0.89(0.59-1.34)$ & 0.60 & 0.07 \\
\hline \multicolumn{5}{|l|}{ ATM } \\
\hline rs1800057 & 0.034 & $10.93(1.35-88.31)$ & 0.01 & 0.53 \\
\hline \multicolumn{5}{|l|}{ DPF3 } \\
\hline rs49030664 & 0.979 & $1.04(0.69-1.55)$ & 0.91 & 0.93 \\
\hline \multicolumn{5}{|l|}{ ALDH9A1 } \\
\hline rs3845536 & 0.015 & $0.62(0.41-0.93)$ & 0.02 & 0.76 \\
\hline \multicolumn{5}{|l|}{ EPAS1 } \\
\hline rs7579899 & 0.977 & $1.02(0.69-1.52)$ & 0.91 & 0.64 \\
\hline
\end{tabular}

${ }^{a} x^{2}$ test or Fisher's exact test. P1: Genotypic frequencies $p$ value. P2: Allelic frequencies p value. OR: Odds Ratio. Cl: Confidence Interval

all conformed to Hardy-Weinberg equilibrium. Similar frequencies in the distribution of $r s 1642742 A / G$ and $r s 779805 A / G$ polymorphisms of $V H L$ were found between healthy controls and RCC patients $(p=0.66$ and $p=0.69$, respectively) for genotypic frequencies, and ( $p=0.61$ and $p=0.61$, respectively) for allelic frequencies. No significant differences in genotypic and allelic frequencies of VEGF polymorphisms were also observed between RCC patients and controls $(p=0.771$, 0.416 , and 0.475 for $+405 C / G,-2578 C / A$ and $-460 T / C$, respectively).

Regarding the polymorphisms (rs1800057C/G, $r s 4381241 T / C, \quad r s 10396602 T / C, \quad 2241261 C / T$, $11813268 \mathrm{C} / \mathrm{T}, \quad 49030664 \mathrm{~T} / \mathrm{C}, \quad 3845536 \mathrm{C} / \mathrm{T}$, rs7579899A/G and rs67311347G/A) in ATM, FAF1, LRRIQ4, RHOBTB2, OBFC1, DPF3, ALDH9A1 and EPAS1 genes, respectively, an association with RCC was found in ATM rs1800057and ALDH9A1 rs3845536 polymorphisms $(p=0.034$ and $p=0.015$ for genotypic frequencies, respectively).

As shown in Table 3, the patients with CG genotype of ATM P1054R variant, had significantly higher risk 
Table 3 Association between SNPs rs67311347, ATM rs 1800057 and ALDH9A1 rs3845536 and risk of RCC

\begin{tabular}{|c|c|c|c|c|c|}
\hline Polymorphisms & Cases $n \%$ & Controls $n \%$ & $P^{\mathrm{a}}$ & OR $(95 \% \mathrm{CI})^{\mathrm{a}}$ & $P^{\mathrm{a}}$ \\
\hline \multicolumn{6}{|l|}{ rs67311347 } \\
\hline GG (ref) & $29(33.33 \%)$ & $49(42.98 \%)$ & & & \\
\hline GA & $44(50.57 \%)$ & $57(50.00 \%)$ & 0.08 & $1.30(0.71-2.38)$ & 0.44 \\
\hline AA & $14(16.09 \%)$ & $8(7.02 \%)$ & & $2.95(1.10-7.89)$ & 0.03 \\
\hline G allele (ref) & $102(58.62 \%)$ & 155 (67.98\%) & & & \\
\hline A allele & $72(41.38 \%)$ & $73(32.02 \%)$ & & $1.49(0.99-2.25)$ & 0.05 \\
\hline \multicolumn{6}{|l|}{ ATM rs 1800057} \\
\hline CC (ref) & $80(91.95 \%)$ & 113 (99.00\%) & & & \\
\hline CG & $6(6.90 \%)$ & $1(0.88 \%)$ & 0.03 & $8.47(1.00-71.76)$ & 0.04 \\
\hline GG & $1(1.15 \%)$ & $0(0.00 \%)$ & & $\operatorname{lnf}(\operatorname{Inf}-\operatorname{Inf})$ & 0.41 \\
\hline C allele (ref) & 166 (95.40\%) & $227(100.00 \%)$ & & & \\
\hline Gallele & $8(4.60 \%)$ & $1(0.44 \%)$ & & $10.93(1.35-88.31)$ & 0.01 \\
\hline \multicolumn{6}{|l|}{ ALDH9A1 rs3845536 } \\
\hline CC (ref) & $35(40.23 \%)$ & $36(32.43 \%)$ & & & \\
\hline $\mathrm{CT}$ & $46(52.87 \%)$ & $51(45.95 \%)$ & 0.01 & $0.92(0.50-1.71)$ & 0.87 \\
\hline TT & $6(6.90 \%)$ & $24(21.62 \%)$ & & $0.25(0.09-0.70$ & 0.007 \\
\hline Callele & $116(66.67 \%)$ & $123(55.41 \%)$ & & & \\
\hline Tallele & $58(33.33 \%)$ & $99(44.59 \%)$ & & $0.62(0.41-0.93)$ & 0.02 \\
\hline
\end{tabular}

${ }^{a} x^{2}$ test or Fisher's exact test. OR: Odds Ratio. Cl: Confidence Interval

of developing RCC than patients with ATM CC genotype (CG Vs. AA OR $=8.47 ; \mathrm{CI}=1.00-71.76 ; p=0.043$ ). Only one mutated GG genotypes among cases have been observed in our study (1.15\%). Moreover, the difference of $G$ allele frequency was statistically significant in the two groups $(\mathrm{OR}=10.93 ; \mathrm{IC}=1.35-88.31 ; p=0.012)$.

Genotypic distributions of $r s 67311347$ polymorphism had no obvious discrepancies between cases and controls $(p>0.05)$, while mutated genotype AA frequency showed statistically significant difference between case and control groups $(\mathrm{OR}=2.95 ; \mathrm{IC}=1.10-7.89 ; p=0.03)$.

Interestingly, in our population, the TT variant of the rs3845536 ALDH9A1 polymorphism was observed to approach significance for a protective role against $\operatorname{RCC}(\mathrm{OR}=0.26 ; \mathrm{IC}=0.09-0.70 ; p=0.007)$. Likewise, the $A L D H 9 A 1 \mathrm{~T}$ allele was also observed to be significantly reduced in $\mathrm{RCC}$ (and $\mathrm{OR}=0.62$; $\mathrm{IC}=0.41-0.94$; $p=0.02$ ).

Also, ATM rs1800054 and ALDH9A1 rs3845536 polymorphisms did not provide evidence of an association with RCC histologic subtype (clear cell, other) $(p=1$ and $p=0.18$ for genotypic frequencies, respectively) (Table 4).

\section{Discussion}

In the present study, we evaluated the association between 14 SNPs including VEGF (-2578C/A [rs699947], $-460 \mathrm{~T} / \mathrm{C}$ [rs833061] and $+405 \mathrm{C} / \mathrm{G}$ [rs2010963]), VHL (rs1642742 and rs779805), FAF1 (rs4381241),
Table 4 Association of the ATM rs1800057 and ALDH9A1 rs3845536 genotypes with RCC histologic type

\begin{tabular}{|c|c|c|c|c|}
\hline \multirow{2}{*}{$\begin{array}{l}\text { Genotype } \\
\text { ATM rs1800057 }\end{array}$} & \multicolumn{2}{|c|}{ Histopathology } & \multirow[t]{2}{*}{ OR $(95 \% \mathrm{Cl})$} & \multirow[t]{2}{*}{$P^{a}$} \\
\hline & Clear cell (n) & Other $(n)$ & & \\
\hline CC (ref) & 50 & 30 & & \\
\hline CG & 3 & 3 & $1.65(0.2-13.2)$ & 0.67 \\
\hline $\mathrm{CG}+\mathrm{GG}$ & 4 & 3 & $1.25(0.17-7.9)$ & 1 \\
\hline C allele (ref) & 103 & 63 & & \\
\hline G allele & 5 & 3 & $0.98(0.14-5.24)$ & 1 \\
\hline \multicolumn{5}{|l|}{ ALDH9A 1 rs3845536 } \\
\hline CC (ref) & 25 & 10 & & \\
\hline $\mathrm{CT}$ & 26 & 20 & $1.9(0.69-5.53)$ & 0.24 \\
\hline TT & 3 & 3 & $2.44(0.28-21.50)$ & 0.36 \\
\hline $\mathrm{CT}+\mathrm{TT}$ & 29 & 23 & $1.97(0.73-5.57)$ & 0.18 \\
\hline Callele & 76 & 40 & & \\
\hline Tallele & 32 & 26 & $1.54(0.77-3.1)$ & 0.19 \\
\hline
\end{tabular}

${ }^{a} x^{2}$ test or Fisher's exact test. OR: Odds Ratio. Cl: Confidence Interval. ${ }^{\text {bD Due to }}$ the small number of homozygous variant alleles, the combined results for the heterozygous and homozygous variant alleles are shown

LRRIQ4 (rs10936602), RHOBTB2 (rs2241261), OBFC1 (rs11813268), ATM (rs1800057), DPF3 (rs49030664), ALDH9A1 (rs3845536), EPAS1 (rs7579899) and rs67311347 and the risk of RCC. Only ATM (rs1800057) was found to be significantly correlated to RCC risk. Interestingly, the rs3845536 ALDH9A1 polymorphism shows a protective effect. To the best of our knowledge, 
the present study is the first that investigated the association of these polymorphisms and RCC risk in Algerian population.

In clear-cell renal carcinoma, the $V H L$ tumor suppressor gene is frequently inactivated leading to $V E G F$ overexpression [1]. $-2578 \mathrm{C} / \mathrm{A},+460 \mathrm{~T} / \mathrm{C},+405 \mathrm{C} / \mathrm{G}$ polymorphisms were among the most common of all the SNPs of VEGF gene investigated. The previously published data have reported that these polymorphisms might be risk factors for RCC especially in Asian population $[11,12]$ (Table 5), although our results showed that no significant associations were found between the $V H L$ and VEGF functional polymorphisms and RCC susceptibility. Similarly to our results Sáenz-López and al [13] reported that $-2578 \mathrm{C} / \mathrm{A},-460 \mathrm{~T} / \mathrm{C},-405 \mathrm{C} / \mathrm{G},-936 \mathrm{C} / \mathrm{T}$ VEGF polymorphisms do not appear to exert a significant effect on RCC risk in Spanish population. Regarding
VHL gene polymorphisms (rs1642742 and rs779805), numerous studies have examined the association with development and/or prognosis of RCC but with inconclusive results $[14,15]$ (Table 5). It has reported that the existence of $\mathrm{G}$ allele at both rs1642742 and rs779805 may play an important role in tumorigenesis of RCC through methylation of $\mathrm{CpG}$ island to suppress gene expression [15]. These discrepancies might depend on ethnicity or the different carcinoma types. Therefore, the VEGF gene polymorphisms may possibly be associated with overproduction of this cytokine that might influence tumor progression in RCC. Moreover, many studies indicated that $-2578 \mathrm{C} / \mathrm{A},-460 \mathrm{~T} / \mathrm{C},-405 \mathrm{C} / \mathrm{G}$ polymorphisms may have an effect on progression and behavior of this cancer [16-18].

Recently, several genome-wide association studies have been interested on renal cell carcinoma, in the aim

Table 5 List of recent studies and meta-analysis regarding the 14 tag-SNPs investigated

\begin{tabular}{|c|c|c|c|c|c|}
\hline Cene & 1st Author, Year & Population & Case/Control & SNP & $P$ value \\
\hline \multicolumn{6}{|l|}{ VEGF } \\
\hline \multirow[t]{3}{*}{ Meta-analyses (8 studies) } & Gong M, 2016 & Asian/Caucasian & $1.397 / 2.094$ & rs699947 & * \\
\hline & & & $262 / 477$ & rs2010963 & NA \\
\hline & & & $677 / 1.299$ & rs833061 & NA \\
\hline \multirow[t]{3}{*}{ Meta-analyses (14 studies) } & Tang J, 2017 & Asian/Caucasian & $1588 / 2470$ & rs699947 & * \\
\hline & & & $1086 / 1460$ & rs2010963 & * \\
\hline & & & $677 / 1299$ & rs833061 & NA \\
\hline \multirow[t]{2}{*}{ Meta-analyses ( 9 studies) } & Hou Q, 2017 & Asian/Caucasian & $1588 / 2470$ & rs699947 & * \\
\hline & & & $2315 / 3552$ & rs2010963 & * \\
\hline \multicolumn{6}{|l|}{ VHL } \\
\hline & Qin C, 2011 & China & $620 / 632$ & rs779805 & NA (0.96) \\
\hline & Wang W, 2014 & China & $19 / 616$ & rs779805 & * \\
\hline & & & & rs1642742 & * \\
\hline & Lv C, 2015 & China & $81 / 80$ & rs7798005 & $*(0.01)$ \\
\hline \multicolumn{6}{|l|}{ EPAS1 } \\
\hline \multirow[t]{5}{*}{ GWAS } & Purdue MP, 2011 & European & $2278 / 3719$ & rs7579899 & $*\left(2.3 \times 10^{-9}\right)$ \\
\hline & Cao Q, 2011 & China & $710 / 760$ & & NA $(0.46)$ \\
\hline & SuT, 2013 & China & $400 / 806$ & & NA $(0.43)$ \\
\hline & Purdue MP, 2014 & African Americans & $255 / 375$ & & NA $(0.86)$ \\
\hline & Melkonian SC, 2014 & Texas & 659/699 & & $*(0.02)$ \\
\hline \multicolumn{6}{|l|}{ ALDH9A1 } \\
\hline GWAS & Henrion MYR, 2015 & Western-European & $2.215 / 8.566$ & rs3845536 & $*\left(2.30 \times 10^{-8}\right)$ \\
\hline \multicolumn{6}{|l|}{ ATM } \\
\hline GWAS & Scelo G, 2017 & European & $10.784 / 20.406$ & rs1800057 & $*\left(9.0 \times 10^{-9}\right)$ \\
\hline FAF1 & / & & & rs4381241 & $*\left(3.1 \times 10^{-10}\right)$ \\
\hline LRRIQ4 & / & & & rs10936602 & $*\left(8.8 \times 10^{-9}\right)$ \\
\hline RHOBTB2 & / & & & rs2241261 & $*\left(5.8 \times 10^{-9}\right)$ \\
\hline$O B F C 1$ & / & & & rs11813268 & $*\left(3.9 \times 10^{-8}\right)$ \\
\hline DPF3 & / & & & rs49030664 & $*\left(2.2 \times 10^{-24}\right)$ \\
\hline- & / & & & rs67311347 & $*\left(2.5 \times 10^{-8}\right)$ \\
\hline
\end{tabular}

*Significant association between SNP and RCC, NS: not significant 
to indentify additional RCC common risk loci and new prognostic biomarker for this cancer. We therefore investigated some of these loci and detected that ATM P1054R variant is likely to directly affect the risk of malignancy. Our data indicate that homozygous carries of the P1054R variant and heterozygous present a significant association with RCC compared with carriers of homozygous wild-type genotype, SNPs in ATM predicted to be deleterious. The ATM missense substitution P1054R can be a genuine $A T M$ mutation seems the rarity of this polymorphism $(\mathrm{MAF}=0.02)[19]$, and because it causes a significant amino acid change in a conserved part of the protein (nonpolar to polar), and it was demonstrated that the presence of such variant may have a functional consequences on an in vitro cellular phenotype [20]. Heterozygous for $P 1054 R$ has been reported to be associated with decreased ATM expression in CLL [19], also increased prostate cancer risk [21]. Furthermore, recent studies are reported the implication of ATM mutations and variants in several other cancers likely oral [22], lung [23] and breast cancer [24]. To the best of our knowledge, there have been no published reports on ATM gene variants and RCC risk. So further understanding of the function of the ATM protein and it's implication in carcinogenesis may explain the known genetic susceptibility to this disease. ATM plays a critical role in maintenance of genomic integrity. Is activated primarily in response to doublestrand breaks, leads to $A T M$-dependent phosphorylation of variety of proteins including P53, BRCA1, c-Abl and CHEK2 involved in checkpoint function, transcription activation and DNA repair [25]. Thus, gene-gene interaction of the ATM gene with CHEK2 was reported to predispose to chronic lymphocytic leukemia (CLL) [26], and breast cancer [27]. Knowing that, CHEK2 has been also associated with increased risk of colon, prostate and kidney cancer [28]. The major cytotoxic lesion induced DNA damage caused by ionizing radiation. Furthermore, it has been reported that ATM genetic polymorphisms interacted with radiation exposure, resulting an effect in carcinogenesis $[29,30]$. Indeed, the linked heterozygous F858L and P1054R variants are documented to confer an increased radiosensitivity in cell lines from breast cancer [20]. Knowing well, that obviously the radiotherapy is not the treatment adopted for renal cancer. We can suggest that this variant may increase the risk of RCC independently of radiotherapy treatment, highlighting that this SNP may have a role in modifying the ATM gene function and consequently altering DNA repair mechanisms.

The mutated genotype AA of $r s 67311347$ polymorphism, appear to exert a significant effect on RCC risk in our population. This SNP has previously been definitively associated with RCC in a large GWAS [7]. The risk associated allele of $r s 67311347$ was associated with a higher expression of ZNF620. This gene encodes the Zinc finger protein 620 , but the function of this protein has not been well described [7].

rs3845536 ALDH9A1 is a new common variant on chromosome 1q24.1 reported in a genome-wide metaanalysis study as a potential risk for renal cancer [8]. The aldehyde dehydrogenase (ALDH) superfamily of enzymes comprises 19 human isozymes involved in detoxification of specific endogenous and exogenous aldehydes substrates [31, 32]. The ability of the ALDH family members to metabolise reactive aldehydes represents a major underlying cytoprotective mechanism, whereas mutations in $A L D H$ genes that lead to a defective aldehyde metabolism are the molecular basis for several diseases, and may contribute to the etiology of cancer [32]. ALDH9A1 encodes $\gamma$-trimethylaminobutyraldehyde dehydrogenase that participates in the metabolism of $\gamma$-aminobutyraldehyde and aminoaldehydes derived from polyamines, with high levels expression are observed in kidney [8, 33]. Interestingly, in our study rs3845536 $A L D H 9 A 1$ polymorphism was associated with a reduced risk of RCC. This variant is intronic to $A L D H 9 A 1$, and the transition $\mathrm{C} \rightarrow \mathrm{T}$ is silent [34]. Although a SNP in intronic region would not influence the protein sequence, it might generate splice variants of transcripts and promote or disrupt binding and function of long noncoding RNAs (lncRNAs) [35]. However, Henrion et al. have reported that variation at 1q24.1 represents a potential risk locus for RCC. But they didn't observe any association between rs3845536 genotype and ALDH9A1 expression. Also no association was detected for any other cancers [8]. This polymorphism was mentioned only in three publications all of them examined the association of SNPs with RCC $[7,8,36]$.

Table 5 shows an overall view of the results of different studies evaluated the association between the 14 test SNPs and RCC.

The present study suggests an eventual association between ATM rs1800057 and ALDH9A1 rs3845536 variants and RCC. These SNPs were first discovered in GWAS in cases of European ancestry [7, 8]. There have been six risk loci identified for renal cell carcinoma, all of which were identified in GWAS in European ancestry population [37]. There is only one GWAS conducted among African Americans population; where, they observed an association of the 11q13.3 variant rs7105934 with reduced RCC risk, consistent with European ancestry GWAS findings; However, the association did not reach genome-wide significant $[37,38]$. The identification of disease-associated SNPs by GWAS tends to have low concordance when different populations are compared. This is seen with prostate cancer, which is the most cancer studied by GWAS in diverse populations 
[37, 39]. Most large-scale GWAS have been carried out in European populations, but there have been studies investigating common risk variants in other ethnic groups and population-specific differences have been reported [39]. Moreover, genome scan study of prostate cancer in Arabs, demonstrated differences between Tunisians and Arab ancestry living in Qatar and Saudi Arabia by the identification of three genomic regions with multiple prostate cancer susceptibility loci in Tunisians [40]. It was also observed that the established markers do not necessarily replicate among inter-Arabic population groups. For example, Mtiraoui et al. illustrated differences between the North African Arabs (from Tunisia) and Levant Arabs (from Lebanon) by demonstrated differential contributions of T2DM susceptibility loci [41]. Population structure in North Africa is particularly complex, and disease or phenotypic studies should carefully $[42,43]$. Within the North African context, the genetic composition of the Algerian population is an amalgam of different ancestral component coming from the middle East, Europe, sub-Saharan Africa and autochthonous to North Africa (Maghrebi) [43]. For this, it's not evident to compare populations of North Africa with only Arab and/or European populations. Additional functional studies are required to have a good investigation specific to the North African population.

Our study has some limitations. First, our sample size may not have enough statistical power to explore the real association and, as such, significant finding should be interpreted cautiously. Data on RCC and rare diseases in Algeria and North Africa remain scarce because of the limited resources in biomedical research. Moreover, the lack of biological sample collection structure has driven researchers to focus much more on the most prevalent diseases. Another limitation association with this investigation is that the increase in family wise error rate across the reported statistical analyses was not controlled. Overall, we consider this research relatively preliminary and encourage replication.

\section{Conclusion}

Our findings suggest that the ATM rs 1800057 polymorphism may contribute to influence development of renal cancer. Thus, the possible role of the ATM gene in cancer predisposition in the general population makes this gene a potential target for screening. Our study suggests also that the ALDH9A rs3845536 polymorphism was associated with reduced risk of RCC in Algeria. Specifically, TT mutated homozygous is associated with a lower risk of RCC than CC or CT genotype. In silico and subsequent RT-PCR analyses are needed to predict the effect of the $r s 3845536$ ALDH9A1 variant on the efficiency of splicing. Further genotyping studies are warranted in a larger number of patients and controls.

\begin{abstract}
Abbreviations
RCC: Renal cell carcinoma; SNP: Single nucleotide polymorphism; GWAS: Genome-wide association study; VHL: Von Hippel-Lindau; VEGF: Vascular endothelial growth factor; ATM: Ataxia telangiectasia mutated; ALDH9A1: Aldehyde dehydrogenase 9 family member A1.
\end{abstract}

\section{Acknowledgements}

We would like to thank all the staff of nephrology laboratory, health research institute of Santiago de Compostela, Spain, for their help and assistance.

\section{Authors' contributions}

FZB gave idea protocol/project development, data collection or management, data analysis, and manuscript writing/editing. DR helped in protocol/ project development, manuscript writing/editing and final correction of the manuscript; MAG and NC helped in data analysis; NA helped in protocol/ project development; AD was thesis advisor; D.S helped in protocol/project development and final correction of the manuscript. Allauthors read and approved the final manuscript.

\section{Funding}

This study had no funding from any resource.

\section{Availability of data and materials}

The data sets used and/or analyzed during the current study are available from the corresponding author on reasonable request.

\section{Ethics approval and consent to participate}

The ethics committee of the Dr BENBADIS - Constantine University Hospital Centre has approved the study. The use of human blood sample and the protocol in this study strictly conformed to the principles expressed in the Declaration of Helsinki. We work in accordance with the Declaration of Helsinki (1964): Ethical principles applicable to medical research on human subjects and in accordance with the recommendations of the Algerian national council for ethics in health sciences. Informed consent (written) was obtained from all participants.

\section{Consent for publication}

All patients included in this research gave written informed consent to publish the data contained within this study.

\section{Competing of interests}

The authors declare that they have no competing interests.

\section{Author details}

${ }^{1}$ Department of Animal Biology, Laboratory of Molecular and Cellular Biology, University Constantine 1, Constantine 25000, Algeria. ${ }^{2}$ Laboratory of Biology and Molecular Genetics, University Constantine 3, 25000 Constantine, Algeria. ${ }^{3}$ Health Research Institute of Santiago (IDIS), Group of Genetics and Developmental Biology of Renal Diseases, Santiago de Compostela, Spain. ${ }^{4}$ Department of Urology and Renal Transplantation, Hospital of Uro-Nephrology, Daksi, 25000 Constantine, Algeria.

Received: 31 October 2019 Accepted: 20 July 2020

Published online: 30 September 2020

References

1. Bray F, Ferlay J, Soerjomataram I (2018) Global Cancer Statistics 2018: GLOBOCAN estimates of incidence and mortality worldwide for 36 cancers in 185 countries. CA Cancer J Clin 68:394-424

2. Prada JG (2018) Review epidemiology of renal cancer in developing countries: review of the literature. Can Urol Assoc J 12(3):54-62

3. Campbell SC, Yong H, Jacqmin D, Eun J, Weikert S, Kiemeney LA (2011) The epidemiology of renal cell carcinoma. Eur Urol 60:615-621 
4. Cho E, Adami H (2011) Epidemiology of renal cell cancer. Hematol Oncol Clin 25:651-665

5. The Cancer Genome Atlas Research Network (2013) Comprehensive molecular characterization of clear cell renal cell carcinoma. Nature 24:3-9

6. Linehan WM (2003) Molecular targeting of the VHL gene pathway. J Uro 170(8):593-594

7. Scelo G (2017) Genome-wide association study identifies multiple risk loci for renal cell carcinoma. Nat Commun 3:1-9

8. Henrion MYR, Purdue MP, Scelo G, Broderick P (2015) Common variation at 1q24. 1 (ALDH9A1) is a potential risk factor for renal cancer. PLoS ONE 1:1-11

9. Purdue MP, Johansson M, Zelenika D, Toro JR, Moore LE, Prokhortchouk E et al (2012) Genome-wide association study of renal cell carcinoma identifies two susceptibility loci on 2 p21 and 11p13.3. Nat Genet 43(1):60-65

10. Miller SA, Dykes DD, Polesky HF (1988) A simple salting out procedure for extracting DNA from human nucleated cells. Nucl Acids Res 16(3):55404

11. Qin C, Cao Q, Ju X, Wang M, Meng X, Zhu J et al (2012) The polymorphisms in the VHL and HIF1A genes are associated with the prognosis but not the development of renal cell carcinoma. Ann Oncol 23(4):981-989

12. Wang W, Tsou M, Chen H, Hsu W, Lai Y (2014) Two single nucleotide polymorphisms in the von Hippel-Lindau tumor suppressor gene in Taiwanese with renal cell carcinoma. BMC Res Notes 7:1-8

13. Sáenz-lópez P, Vazquez F, Manuel J, Carretero R, Garrido F, Ruiz-cabello F (2013) VEGF polymorphisms are not associated with an increased risk of developing renal cell carcinoma in Spanish population. Hum Immunol 74:98-103

14. Tang J, Qin Z, Li X, Han P, Wang F (2017) Association between vascular endothelial growth factor gene polymorphisms and the risk and prognosis of renal cell carcinoma: a systematic review and meta-analysis. Oncotarget 8(30):50034-50050

15. Hou Q, Li M, Huang W, Wei F, Peng J (2017) Association between three VEGF polymorphisms and renal cell carcinoma susceptibility: a metaanalysis Study characteristics. Oncotarget 8(30):50061-50070

16. Kawai Y, Sakano S, Korenaga Y, Eguchi S, Naito K (2007) Associations of single nucleotide polymorphisms in the vascular endothelial growth factor gene with the characteristics and prognosis of renal cell carcinomas. Eur Urol 52:1147-1155

17. Zhong W, Wang X, Pan B, Su Z (2014) Association of vascular endothelial growth factor polymorphisms with clinical outcome of renal cell carcinoma patients. Tumor Biol 35:9839-9845

18. Ma NAN, Li LIWEl, Cheng JL (2015) Predictive value of vascular endothelial growth factor polymorphisms on the clinical outcome of renal cell carcinoma patients. Oncol Lett 9:651-656

19. Stankovic T, Weber P, Stewart G, Bedenham T, Murray J, Byrd PJ et al (1999) Inactivation of ataxia telangiectasia mutated gene in B-cell chronic lymphocytic leukaemia. Lancet 353:26-29

20. Gutie S, Fernet M, Do T, Bremer M, Lauge A, Stoppa-lyonnet D et al (2004) Functional consequences of ATM sequence variants for chromosomal radiosensitivity. Genes Chromosom Cancer 40(1):109-119

21. Meyer A, Wilhelm B, Do T, Bremer M, Baumann R, Hinrich J et al (2007) Molecular oncology ATM missense variant P1054R predisposes to prostate cancer. Radiother Oncol 83:283-288

22. Bau D, Chang C, Tsai M, Chiu C (2010) Association between DNA repair gene ATM polymorphisms and oral cancer susceptibility. Laryngoscope 120(12):2417-2422

23. Yan Z, Tong X, Ma Y, Liu S, Yang L, Yang $X$ et al (2017) Association between ATM gene polymorphisms, lung cancer susceptibility and radiationinduced pneumonitis: a meta-analysis. BMC Pulm Med 17:1-8

24. Bubien V, Bonnet F, Dupiot-chiron J, Jones EBN, Sevenet N, Longy M et al (2017) Combined tumor genomic profiling and exome sequencing in a breast cancer family implicates ATM in tumorigenesis: a proof of principle study. Genes Chromosomes Cancer 56:788-799

25. Khanna K (2000) Cancer risk and the ATM gene: a continuing debate. J Natl Cancer Inst 92(10):795-802

26. Rudd MF, Sellick GS, Webb EL, Catovsky D, Houlston RS (2006) Variants in the ATM - BRCA2-CHEK2 axis predispose to chronic lymphocytic leukemia. Neoplasia 108(2):638-645

27. Byrnes GB, Southey MC, Hopper JL (2008) Review Are the so-called low penetrance breast cancer genes, ATM, BRIP1, PALB2 and CHEK2, high risk for women with strong family histories? Breast Cancer Res 10:1-7

28. Cybulski C, Go B, Huzarski T, Masojc B, Mierzejewski M, Teodorczyk U et al (2004) CHEK2 Is a multiorgan cancer susceptibility. Gene Hum Genet 75:1131-1135

29. Zhao Y, Yang L, Wu D, He H, Wang M, Ge T (2016) Gene-environment interaction for polymorphisms in ataxia telangiectasia-mutated gene and radiation exposure in carcinogenesis: results from two literature-based meta-analyses of 27120 participants. Oncotarget 10:1-15

30. Athma P, Rappaport R, Swift M (1996) Molecular genotyping shows that ataxia-telangiectasia heterozygotes are predisposed to breast cancer. Cancer Genet Cytogenet 92:130-134

31. Pors K, Moreb JS (2014) Aldehyde dehydrogenases in cancer: an opportunity for biomarker and drug development? Drug Discov Today 19(12):1953-1963. https://doi.org/10.1016/j.drudis.2014.09.009

32. Jackson B, Brocker C, Thompson DC, BlackW, Vasiliou K, Nebert DW et al (2011) Update on the aldehyde dehydrogenase gene (ALDH) superfamily. Hum Genom 5(4):283-303

33. Muzio G, Maggiora M, Paiuzzi E, Oraldi M, Canuto RA (2012) Aldehyde dehydrogenases and cell proliferation. Free Radic Biol Med 52(4):735-746. https://doi.org/10.1016/j.freeradbiomed.2011.11.033

34. Yoshida A, Rzhetsky A, Hsu LC, Chang C (1998) Review Human aldehyde dehydrogenase gene family. Eur J Biochem 251:549-557

35. Deng N, Zhou H, Fan H, Yuan Y (2017) Single nucleotide polymorphisms and cancer susceptibility. Oncotarget 8(66):110635-110649

36. Grampp S, Schmid V, Salama R, Lauer V, Kranz F, Platt JL et al (2017) Multiple renal cancer susceptibility polymorphisms modulate the HIF pathway. PLoS Genet 13(7):1-23

37. Park SL, Cheng I, Haiman CA (2018) Genome-wide association studies of cancer in diverse populations. Cancer Epidemiol Biomark Prev 27(4):405-418

38. Purdue MP, Ye Y, Wang Z, Colt JS, Schwartz KL, Davis FG et al (2014) A genome-wide association study of renal cell carcinoma among African Americans. Cancer Epidemiol Biomark Prev 2:209-215

39. Benafif S, Kote-jarai Z, Eeles RA, Hospital RM, Road F (2019) A review of prostate cancer genome wide association studies (GWAS). Cancer Epidemiol Biomark Prev 27(8):845-857

40. Shan J, Al-rumaihi K, Rabah D, Al-bozom I, Kizhakayil D, Farhat Ket al (2013) Genome scan study of prostate cancer in Arabs: identification of three genomic regions with multiple prostate cancer susceptibility loci in Tunisians. BioMed Central 11(1):121

41. Mtiraoui N, Turki A, Nemr R, Echtay A, Izzidi l, Al-zaben GS et al (2012) PPAR Y, SLC30A8 and TCF7L2 to the risk of type 2 diabetes in Lebanese and Tunisian Arabs. Diabetes Metab 38(5):444-449. https://doi. org/10.1016/j.diabet.2012.05.002

42. Bekada A, Arauna LR, Deba T, Calafell F (2015) Genetic heterogeneity in Algerian human populations. PLoS ONE 10(9):1-15

43. Gravel S, Wang W, Brisbin A, Byrnes JK, Henn BM, Botigue LR et al (2012) Genomic ancestry of North Africans supports Back-to-Africa migrations PLoS Genet 8(1):1-11

\section{Publisher's Note}

Springer Nature remains neutral with regard to jurisdictional claims in published maps and institutional affiliations. 